\title{
Cypriot Journal of Educational Sciences
}

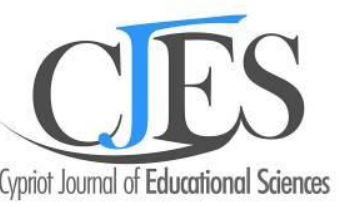

www.cjes.eu

\section{Systemic intelligence predictors of cognitive flexibility and cognitive holding power among university students}

Emad Mohamad Alzubi a * , Al Balqa' Applied University, Jordan https://orcid.org/0000-0003-2627-2402

Madher Mohammad Attiat ${ }^{\text {b }}$, Al Balqa' Applied University, Jordan https://orcid.org/0000-0002-9114-889X

Omar Atallah Al-Adamat c, Ministry of Education, Jordan, https://orcid.org/0000-0002-9767-5754

\section{Suggested Citation:}

Alzubi, E. M; Attiat, M. M. \& Al-Adamat, O. A. (2022). Systemic intelligence predictors of cognitive flexibility and cognitive holding power among university students. Cypriot Journal of Educational Science. 17(2), 491505. https://doi.org/10.18844/cjes.v17i2.6835

Received from October 10, 2021; revised from December 15, 2021, accepted from February 22, 2022 ${ }^{\circ} 2022$ Birlesik Dunya Yenilik Arastirma ve Yayincilik Merkezi. All rights reserved.

\begin{abstract}
This study aimed to investigate the role of systemic intelligence factors in explaining cognitive flexibility and cognitive holding power among university students using measures of the aforementioned phenomena. A random sample of (519) students participated in this research, and it was found that factors relating to systemic intelligence could predict cognitive flexibility and cognitive holding power. The elements of systemic intelligence that were most adept at explaining cognitive flexibility were systemic action through positive engagement and active response, while systemic perception was the most explanatory factor in terms of cognitive holding power. The study concluded that systemic intelligence, which has perceptual, cognitive, social and behavioural facets, contributes to student performance in learning settings; consequently, it is recommended that the role of systemic intelligence should be analysed by linking elements of this form of intelligence with the different variables and integrating systemic thinking skills into different learning activities.
\end{abstract}

Keywords: systemic intelligence, cognitive flexibility, cognitive holding power.

\footnotetext{
* ADDRESS FOR CORRESPONDENCE: Emad Mohamad Alzubi, Princess Rahma University College, Al-Balqa Applied University, Salt, Jordan.

E-mail address: demad73@bau.edu.jo / Tel.: +962799414009
} 


\section{Introduction}

\subsection{Concept}

Positive psychology and related psychological, educational and social issues have gained popularity in recent years. This approach focuses on the positive aspects that promote psychosocial adjustment, well-being, happiness and quality of life. Systemic intelligence ( $\mathrm{SI}$ ) is one of the most prominent outcomes of scientific research with regard to the biological phenomena of human intelligence and refers to successful and productive behaviour within the context of complex systems, which include the overall interaction with and the feedback from environmental stimuli (Rauthmann, 2010; Ranne, 2007; Saarinen \& Hamalainen, 2007). It entails intense sensing and thinking about the surrounding system's components to implement adaptive productive actions within various systemic contexts (Hamalainen \& Saarinen, 2010).

Furthermore, its related abilities are identified in terms of various dimensions: systemic perception, systemic feeling, systemic thinking and systemic action (Tormanen, 2012; Rauthmann, 2010). Saarinen and Hamalainen (2007) also added managing SI and management using SI. Moreover, previous models have demonstrated that perceptual and cognitive processes are an essential component of SI, cognitive flexibility (CF) and cognitive holding power (CHP), they are among the most valuable skills that an individual needs to confront challenging situations that involve active interaction and successful management of feedback as well as new and unexpected situations (Canas et al., 2005). However, cognitive flexibility and cognitive holding power also require the capability to perceive similarities and differences with regard to an internal relationship (Murray et al., 1990). Meanwhile, the significance of SI lies in its ability to increase response speed as well as its capacity to improve understanding of and influence over the surrounding environment (Rauthmann, 2010).

Cognitive flexibility is an individual's mental ability to control cognitive structures and practice information-processing strategies to meet new and unexpected conditions in complex systems (Somuncu, 2016; Dennis et al., 2010; Deak, 2003; Sternberg, 1985; Gunduz, 2013). It is represented in the dynamic production and transformation of the flow of ideas (Miyake et al., 2000; Ran et al., 2009; Tan, 2005; Shah, 2003; Dennis \& Vander, 2010; Canas et al., 2005). There are two types of cognitive flexibility: adaptive and automatic (Ran et al., 2009). Adaptive flexibility refers to an individual's ability to change their way of thinking and to seek appropriate solutions when they encounter a challenging situation. Meanwhile, automatic flexibility equates to the capacity to smoothly generate as many diverse ideas as possible about a situation. Dennis and Vander (2010) identified three components of cognitive flexibility: the ability to perceive multiple alternative interpretations of life events and situations, the ability to come up with multiple alternative solutions to difficult problems and the ability to identify and manage difficult situations.

Leading on from this, cognitive holding power is a psychological and social concept that is related to cognitive and mental activities (Stevenson \& Mckavanagh, 2002). It is defined as the degree to which the learning environment encourages students to use different cognitive procedures in a specific field during the learning process (Stevenson, 1990; Walmsley, 2003; Xin \& Zhang, 2009; Stevenson \& Evans, 1994). These experiences result in two types of motivation. First-order cognitive holding power (FOCHO) is determined by advanced adaptation to the learning environment with the superficial strategy of learning and the use of conventional learning techniques, such as imitation and dependence on the teacher, while not devoting much attention to individual differences. Alternatively, 
the high degree of motivation linked to second-order cognitive holding power (SOCHP) is characterised by deep learning strategies, such as practicing cognitive and metacognitive activities, which urge the learner to produce ideas, link new information with previous knowledge and develop appropriate strategies (Hunt \& Stevenson, 1997; Stevenson, 1998; Clark \& Dart, 1991; Stevenson \& Mckavanagh, 2002; Stevenson \& Ryan, 1994).

A better understanding of the two levels of cognitive holding power can be achieved through the processes associated with learning settings and teachers'/students' activities. Learning settings are traditional educational environments where the direct implementation of the teacher's instructions takes place; then, the learner imitates what the teacher does and complies with their orders. However, this form of instruction limits the learner's ability to adapt to the tasks and requirements associated with the learning process (Stevenson, 1990).

Conversely, the learning environment of the second level is characterised by setting non-traditional goals that help to process and build knowledge and integrate it with previously acquired information, making the individual a flexible learner who is able to control their learning and thinking and push themselves to self-motivate in order to persevere enough to accomplish the task (Rakibat \& Qatami, 2016; Stevenson \& Evans, 1994).

In terms of the teacher's activities, their experience influences the learner's level of cognitive control. The more experienced a teacher is, the more learning situations they can provide that encourage the practice of procedures, such as self-learning, participation and investigation (Stevenson \& Mckavanagh, 1991). This improves students' respective abilities to think, analyse, link, conclude, present new ideas, ask intelligent questions and make decisions (D'netto, 2004; McCarthy \& Peterson, 1995).

\subsection{Previous Studies}

Numerous studies have linked intelligence and SI with many different cognitive skills. Colzato et al. (2006) claimed that intelligence is positively related to cognitive flexibility, especially when dealing with the content of a situation. Jaber (2016) found a statistically significant relationship between the level of systemic thinking and cognitive flexibility among school principals, while Salami (2017) revealed a positive, statistically significant correlation between SI and metacognitive thinking skills among university students. Furthermore, Saadh (2020) revealed a positive relationship between successful intelligence, positive thinking and the power of cognitive control among university students as well as the direct, statistically significant effect of positive thinking on successful intelligence. This study also revealed the direct, statistically significant influence of positive thinking on cognitive holding power in successful intelligence and the indirect effect of positive thinking on successful intelligence through cognitive holding power. Meanwhile, Sadiq and Atta (2020) uncovered a direct, positive and statistically significant link between perceived quality of life/professional ambition and SI along with a statistically significant indirect relationship between positive thinking and $\mathrm{SI}$ in relation to the professional ambition of schoolteachers.

When reviewing the previous literature relating to $\mathrm{SI}$, we noted the scarcity of studies that dealt with the association between SI and flexibility/cognitive control; therefore, the role of this research is to identify the elements of SI that predict flexibility and cognitive control among university students 
as, in this age group, $\mathrm{SI}$ is considered of great importance for achieving academic, professional and social success.

\subsection{Study Questions}

1.3.1. First question: What is the relative contribution of the factors of systemic intelligence in relation to explaining the cognitive flexibility of university students?

1.3.2. Second question: What is the relative contribution of the factors of systemic intelligence in relation to explaining cognitive holding power among university students?

\section{Method and Materials}

\subsection{Participants}

Of the (519) participants, (233) were male and (286) were female, and they were all enrolled at AlBalqa Applied University in Al-Salt during the summer semester of the (2020/2021) academic year. Furthermore, the study's population accounts for $(7 \%)$ of the total number of attendees, and the sample was chosen with a random cluster method.

\subsection{Instruments}

\subsubsection{The Systemic Intelligence Scale}

The researchers adopted the SI scale, which was developed by Tormanen (2012) and translated into Arabic by Feel (2015). The scale includes (50) items that measure four main factors that are distributed over eight sub-dimensions, namely systemic perception (systemic perception: six items/positivity and Attunement: six items), systemic attitude (positive attitude: nine items/spirited discovery: five items), systemic thinking (reflection: nine items/wise action: five items) and systemic action (positive engagement: five items/active responsiveness: five items) (Tormanen \& Saarinen, 2016).

Using a five-point Likert scale (always: five; often: four; sometimes: three; rarely: two; never: one), the validity of the scale was tested by a specialised committee in educational psychology, measurement and evaluation, and all of the required modifications were made.

The construct validity of the scale was verified after applying it to (43) male and female students by means of the convergent validity index between the dimensions of the SI scale where the correlation coefficients were ranged between $(0.234)$ and $(0.719)$, and the sub-dimensions were linked to the abilities (factors) they belong to. The correlations of the sub-dimensions with the abilities (factors) they belong to were higher than their correlation with other abilities, and the correlations of the SI factors ranged between $(0.434)$ and $(0.769)$ where all correlation coefficients were statistically significant at a level greater than $(\sigma=0.01)$ (see Table 1$)$. The reliability of the internal consistency was also verified using Cronbach's alpha, which ranged between (0.591) and (0.847). 
Table (1). Detailed Matrix of Correlation Coefficients Between Dimensions and Factors of SI

\begin{tabular}{|c|c|c|c|c|c|c|c|c|c|c|c|c|}
\hline \multirow[b]{2}{*}{ Dimensions } & \multirow[b]{2}{*}{$\begin{array}{l}\text { 음 } \\
\frac{0}{0} \\
\frac{0}{0} \\
\frac{0}{0} \\
\square\end{array}$} & \multicolumn{3}{|c|}{ Factors } & \multicolumn{2}{|c|}{$\begin{array}{l}\text { Systemic } \\
\text { Perception }\end{array}$} & \multicolumn{2}{|c|}{$\begin{array}{l}\text { Systemic } \\
\text { Attitude }\end{array}$} & \multicolumn{2}{|c|}{$\begin{array}{l}\text { Systemic } \\
\text { Thinking }\end{array}$} & \multicolumn{2}{|c|}{$\begin{array}{l}\text { Systemic } \\
\text { Action }\end{array}$} \\
\hline & & 总 & 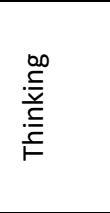 & $\frac{\check{0}}{\stackrel{O}{0}}$ & 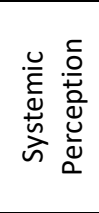 & 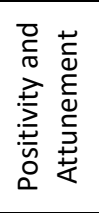 & 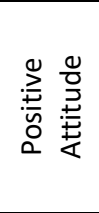 & 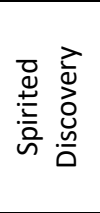 & 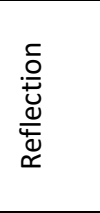 & 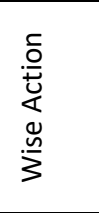 & 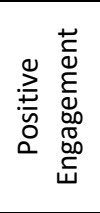 & 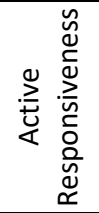 \\
\hline Perception & 1 & $.434 * *$ & $.719 * *$ & $.769 * *$ & $.843 * *$ & $.910 * *$ & $.324 * *$ & $.468 * *$ & $.702^{* *}$ & $.553^{* *}$ & $.737^{* *}$ & $.600 * *$ \\
\hline Attitude & & 1 & $.602 * *$ & $.538 * *$ & $.399 * *$ & $.370 * *$ & $.931 * *$ & $.736^{* *}$ & $.513 * *$ & $.588 * *$ & $.375^{* *}$ & $.578^{* *}$ \\
\hline Thinking & & & 1 & $.779 * *$ & $.611^{* *}$ & $.651^{* *}$ & $.447 * *$ & $.655^{* *}$ & $.942 * *$ & $.824 * *$ & $.669 * *$ & $.694 * *$ \\
\hline Action & & & & 1 & $.618^{* *}$ & $.724 * *$ & $.376 * *$ & $.628 * *$ & $.732 * *$ & $.645^{* *}$ & $.890 * *$ & $.857^{* *}$ \\
\hline Systemic Perception & & & & & 1 & $.544 * *$ & $.288 * *$ & $.447 * *$ & $.604 * *$ & $.456 * *$ & $.558 * *$ & $.519 * *$ \\
\hline Positivity and Attunement & & & & & & 1 & $.283^{* *}$ & $.385^{* *}$ & $.629 * *$ & $.510 * *$ & $.719 * *$ & $.536 * *$ \\
\hline Positive Attitude & & & & & & & 1 & $.438 * *$ & $.369 * *$ & $.456 * *$ & $.234 * *$ & $.437 * *$ \\
\hline Spirited Discovery & & & & & & & & 1 & $.579 * *$ & $.604 * *$ & $.492 * *$ & $.614^{* *}$ \\
\hline Reflection & & & & & & & & & 1 & $.588 * *$ & $.668 * *$ & $.609 * *$ \\
\hline Wise Action & & & & & & & & & & 1 & $.489 * *$ & $.648^{* *}$ \\
\hline Positive Engagement & & & & & & & & & & & 1 & $.527^{* *}$ \\
\hline Active Responsiveness & & & & & & & & & & & & 1 \\
\hline
\end{tabular}

\subsubsection{The Cognitive Flexibility Scale}

The researchers adopted the cognitive flexibility scale prepared by Dennis et al. (2010), which was translated into Arabic by Abdul Wahab (2011) and Draider et al. (2018). It includes (30) items distributed over two dimensions: adaptive flexibility and automatic flexibility. A six-point Likert scale was also used (fully agree: six; agree: five; agree to some extent: four; disagree: three; somewhat disagree: two; not at all: one). The validity of the scale was verified by presenting it to a specialised committee in educational psychology, measurement and evaluation, and modifications were made to the wording of the items.

The construct validity was tested by calculating the correlation coefficients of the items with their dimensions and their correlation with the total score where the correlation coefficient of the items of the adaptive flexibility dimension ranged between $(0.29)$ and $(0.47)$ and the correlation coefficients of the automatic flexibility dimension ranged between $(0.26)$ and $(0.51)$, which function statistically at a level greater than $(\sigma=0.05)$, and the correlations of the items with the dimension to which they belong were higher than their correlation with the other dimensions. The internal consistency coefficients were also found using Cronbach's alpha and ranged between (0.80) and (0.89) for the two dimensions and the total score.

\subsubsection{The Cognitive Holding Power Scale}

The researchers used the cognitive holding power scale, which was designed by Stevenson and Evans (1994) and consists of (30) items that are divided into two sections: the role of the teacher in encouraging students to perform learning tasks (encouragement = eight items) and student performance in the classroom (student motivation dimension = eight items); this is alongside the students' behavioural patterns (14) items. A five-point scale was used (always: five; often: four; 
sometimes: three; rarely: two; never: one). Subsequently, the scale's validity was verified by presenting it to a specialised committee in educational psychology, measurement and evaluation.

The construct validity was confirmed after being applied to (43) students using the convergent validity index with regard to the dimensions of the cognitive holding power scale. The correlation coefficient between the two dimensions within SOCHP (students' motivation and behavioural patterns) was recorded as (0.75), which is higher than its correlation with the cognitive holding power associated with teacher encouragement that ranged between $(0.60)$ and $(0.62)$. The correlations of the items for each dimension were higher than their correlation with the other dimensions.

The internal consistency was also verified using Cronbach's alpha where the related coefficients of the second-order dimensions associated with the student's behaviour patterns while performing learning tasks were (0.774) and (0.846), and the dimension of cognitive holding power associated with the role of the teacher in encouraging students to perform learning tasks was (0.884); both values are considered acceptable for this study.

\subsection{Study Design and Statistical Analysis}

The correlative descriptive approach, which is based on the use of hierarchical multiple regression analysis, was utilised to detect the predictive ability of the factors of system-based intelligence systemic perception, specifically in relation to its two dimensions (systemic perception and positivity and Attunement). Similarly, systemic attitude can be split into two features - positive attitude and spirited discovery - while systemic thinking includes reflection and wise action, and systemic action incorporates positive engagement and active responsiveness. Meanwhile, adaptive and automatic cognitive flexibility and (FOCHP) are associated with the role of the teacher in encouraging students to perform learning tasks, and (SOCHP) is related to student motivation and behavioural patterns when completing learning tasks.

\section{Results}

\subsection{Results of the First Question}

What is the relative contribution of the factors of $\mathrm{SI}$ in relation to explaining the cognitive flexibility of university students? To address this question, Pearson correlation coefficients were obtained with regard to the dimensions of $\mathrm{SI}$ factors (predictors) and the dimensions of cognitive flexibility (predicted), as shown in Table (2).

Table (2). Pearson Correlation Coefficients Between SI Factors and CF Dimensions

\begin{tabular}{|c|c|c|c|c|c|c|c|c|}
\hline \multirow{2}{*}{$\begin{array}{c}\text { Factors of SI } \\
\text { Dimensions of } \\
\text { CF }\end{array}$} & \multicolumn{2}{|c|}{ Perception } & \multicolumn{2}{|c|}{ Attitude } & \multicolumn{2}{|c|}{ Thinking } & \multicolumn{2}{|c|}{ Action } \\
\hline & $\begin{array}{l}\text { Systemic } \\
\text { Cognition }\end{array}$ & $\begin{array}{l}\text { Positivity and } \\
\text { Attunement }\end{array}$ & $\begin{array}{c}\text { Positive } \\
\text { Attitudes }\end{array}$ & $\begin{array}{c}\text { Spirited } \\
\text { Discovery }\end{array}$ & Reflection & Wise Action & $\begin{array}{c}\text { Positive } \\
\text { Engagement }\end{array}$ & $\begin{array}{c}\text { Active } \\
\text { Responsiveness }\end{array}$ \\
\hline $\begin{array}{l}\text { Adaptive } \\
\text { Flexibility }\end{array}$ & $.384 * *$ & $.451 * *$ & $.190 * *$ & $.347 * *$ & $.444^{* *}$ & $.411 * *$ & $.470 * *$ & $.457 * *$ \\
\hline $\begin{array}{c}\text { Automatic } \\
\text { Flexibility }\end{array}$ & $.423 * *$ & $.463 * *$ & $.203 * *$ & $.328 * *$ & $.494 * *$ & $.338 * *$ & $.520 * *$ & $.374 * *$ \\
\hline
\end{tabular}

A positive, statistically significant correlation at a level greater than $\alpha=0.05$ was demonstrated between the dimensions of SI and the dimensions of cognitive flexibility. Meanwhile, the Pearson's correlation coefficients ranged between $(0.203)$ and $(0.52)$. The highest correlation was between 
automatic flexibility and positive engagement (0.52), while the lowest correlation was between automatic flexibility and positive attitude (0.203).

To determine the extent of the contribution of the factors and the dimensions of systems intelligence in predicting and interpreting cognitive flexibility (adaptive flexibility/automatic flexibility), hierarchical multiple regression was completed. The results of this analysis highlighted two predictive equations, as shown in Table (3). After verifying the assumptions of the multiple regression analysis in terms of the linear relationship between the independent variables (predictors) and the dimensions of the dependent variable, most of the correlation coefficients were seen to be greater than (0.30).

As well as the assumption that there is no self-correlation between the predictive variables as the correlations between them did not exceed $(0.70)$ and because there was seemingly no high level of correlation between the independent variables (multicollinearity) in accordance with the variance inflation factor (VIF) where the value of (VIF) did not exceed three, this indicates that there is no linear multiplicity between the independent variables. This is also in line with the tolerance test where the amount of variance for the independent variable was no less than (0.10) (Warner, 2008).

Table (3). Results of the Hierarchical Regression Analysis of Adaptive and Automatic Flexibility on the Dimensions of SI

\begin{tabular}{|c|c|c|c|c|c|c|c|}
\hline $\begin{array}{c}\text { Dimensions of CF } \\
\text { (Predicted) }\end{array}$ & R Square & F Change & $P$ & $\begin{array}{c}\text { Dimensions of SI } \\
\text { (predictors) }\end{array}$ & 8 & $\mathrm{~T}$ & $P$ \\
\hline \multirow{8}{*}{ Adaptive Flexibility } & \multirow{8}{*}{0.303} & \multirow{8}{*}{5.308} & \multirow{8}{*}{0.022} & Systemic Cognition & .053 & .720 & .472 \\
\hline & & & & Positivity \& Attunement & .113 & 1.308 & .192 \\
\hline & & & & Positive Attitudes & -.053 & -.826 & .410 \\
\hline & & & & Spirited Discovery & -.004 & -.044 & .965 \\
\hline & & & & Reflection & .065 & .734 & .463 \\
\hline & & & & Wise Action & .107 & 1.323 & .187 \\
\hline & & & & Positive Engagement & .177 & 1.995 & .047 \\
\hline & & & & Active Responsiveness & .192 & 2.304 & .022 \\
\hline \multirow{8}{*}{$\begin{array}{l}\text { Automatic } \\
\text { Flexibility }\end{array}$} & \multirow{8}{*}{0.322} & \multirow{8}{*}{13.848} & \multirow{8}{*}{0.000} & Systemic Cognition & .105 & 1.458 & .146 \\
\hline & & & & Positivity \& Attunement & .088 & 1.035 & .302 \\
\hline & & & & Positive Attitudes & .014 & .223 & .824 \\
\hline & & & & Spirited Discovery & -.006 & -.072 & .943 \\
\hline & & & & Reflection & .191 & 2.186 & .030 \\
\hline & & & & Wise Action & -.015 & -.185 & .853 \\
\hline & & & & Positive Engagement & .265 & 3.020 & .003 \\
\hline & & & & Active Responsiveness & .024 & .289 & .772 \\
\hline
\end{tabular}

The results of the hierarchical multiple regression analysis showed that the percentage of the cumulative explained variance in terms of adaptive flexibility reached (30.3\%), indicating the existence of a statistical significance at a level greater than $(\sigma=0.05)$. Moreover, the standardised beta coefficient demonstrated that only two dimensions of SI can be used to explain adaptive flexibility, namely positive engagement and active responsiveness. Positive engagement contributed to an increase in adaptive flexibility by $(0.177)$ standard units when positive engagement increased by one standard unit, and active responsiveness contributed to an increase in adaptive flexibility by (0.192) standard units when active responsiveness is increased by one standard unit. Meanwhile, the cumulative explained variance for automatic flexibility with regard to the combined dimensions of $\mathrm{SI}$ reached $(32.2 \%)$, indicating there is a statistical significance at the level of $(\sigma=0.05)$. In addition, the 
beta coefficient suggests that two dimensions of SI contribute to the interpretation of automatic flexibility: reflections increased automatic flexibility by (0.191) standard units when reflection was increased by one standard unit, while positive engagement increased automatic flexibility by (0.265) standard units when it was increased by one standard unit.

\subsection{Results of the Second Question}

What is the relative contribution of the factors of systemic intelligence in relation to explaining cognitive holding power among university students? The Pearson correlation coefficients were obtained with regard to the dimensions of systemic intelligence factors (predictors) and dimensions of cognitive holding power (predicted), as illustrated in Table (4).

Table (4). Pearson's Correlation Coefficients Between the Dimensions of SI and the Dimensions of CHP.

\begin{tabular}{|c|c|c|c|c|c|c|c|c|}
\hline \multirow{2}{*}{$\begin{array}{l}\text { Factors of } \mathrm{SI} \\
\text { Dimensions of } \mathrm{CHP}\end{array}$} & \multicolumn{2}{|c|}{ Perception } & \multicolumn{2}{|c|}{ Attitude } & \multicolumn{2}{|c|}{ Thinking } & \multicolumn{2}{|c|}{ Action } \\
\hline & $\begin{array}{c}\text { Cognitive } \\
\text { Perspective }\end{array}$ & $\begin{array}{l}\text { Positivity and } \\
\text { Attunement }\end{array}$ & $\begin{array}{l}\text { Positive } \\
\text { Attitude }\end{array}$ & $\begin{array}{l}\text { Spirited } \\
\text { Discovery }\end{array}$ & Reflection & $\begin{array}{l}\text { Wise } \\
\text { Action }\end{array}$ & $\begin{array}{c}\text { Positive } \\
\text { Engage-ment }\end{array}$ & $\begin{array}{c}\text { Active } \\
\text { Response }\end{array}$ \\
\hline Teacher Encouragement & $.373^{* *}$ & $.385^{* *}$ & $.150^{*}$ & $.352^{* *}$ & $.428^{* *}$ & $.353^{* *}$ & $.443^{* *}$ & $.356^{* *}$ \\
\hline Student Motivation & $.420^{* *}$ & $.394^{* *}$ & $.248^{* *}$ & $.362^{* *}$ & $.417^{* *}$ & $.372^{* *}$ & $.410^{* *}$ & $.375^{* *}$ \\
\hline Student Behavioural Patterns & $.510^{* *}$ & $.478^{* *}$ & $.336^{* *}$ & $.447^{* *}$ & $.501^{* *}$ & $.488^{* *}$ & $.427^{* *}$ & $.472^{* *}$ \\
\hline
\end{tabular}

There is a positive, statistically significant correlation at a level greater than $(\alpha=0.05)$ between the dimensions of $\mathrm{SI}$ and the dimensions of cognitive holding power, while the Pearson's correlation coefficients ranged between (0.15) and (0.51). The highest correlation was between students' behavioural patterns and systemic cognition (0.51), and the lowest statistical relationship was between teacher encouragement and positive attitude (0.15).

To determine the extent of the contribution of the factors and dimensions of SI (perception: systemic perception, positivity and attunement; attitude: positive direction and spirited discovery; thinking: reflection and wise action; action: positive engagement and active response) when predicting and interpreting cognitive holding power (teacher encouragement, student motivation and student behavioural patterns), a hierarchical multiple regression analysis was conducted as the factors and dimensions of $\mathrm{SI}$ are predictive variables and the dimensions of cognitive holding power are predicted variables.

The predictors were all entered at the same time. In relation to teacher encouragement, student motivation and student behavioural patterns, the results of the hierarchical regression analysis highlighted three predictive equations, see Table (5).

Table (5). Results of Hierarchical Regression Analysis of the Effect of Dimensions of CHP on Dimensions of SI

\begin{tabular}{|c|c|c|c|c|c|c|c|}
\hline $\begin{array}{c}\text { CHP } \\
\text { (predicted) }\end{array}$ & R Square & F Change & $P$ & $\begin{array}{l}\text { Dimensions of SI } \\
\text { Predictors }\end{array}$ & B & $\mathrm{T}$ & $P$ \\
\hline \multirow{5}{*}{ FOCHP } & \multirow{5}{*}{0.25} & \multirow{5}{*}{9.73} & \multirow{5}{*}{0.000} & Systemic Cognition & .095 & 1.251 & .212 \\
\hline & & & & $\begin{array}{l}\text { Positivity and } \\
\text { Attunement }\end{array}$ & .047 & .527 & .599 \\
\hline & & & & Positive Attitudes & -.069 & -1.032 & .303 \\
\hline & & & & Spirited Discovery & .092 & 1.129 & .260 \\
\hline & & & & Reflection & .122 & 1.326 & .186 \\
\hline
\end{tabular}




\begin{tabular}{|c|c|c|c|c|c|c|c|}
\hline & & & & $\begin{array}{c}\text { Wise Action } \\
\text { Positive Engagement } \\
\text { Active Responsiveness }\end{array}$ & $\begin{array}{l}.076 \\
.192 \\
.030 \\
\end{array}$ & $\begin{array}{c}.906 \\
2.084 \\
.349 \\
\end{array}$ & $\begin{array}{l}.366 \\
.038 \\
.728 \\
\end{array}$ \\
\hline \multirow{8}{*}{$\begin{array}{l}\text { SOCHP } \\
\text { (Student } \\
\text { Motivatio) }\end{array}$} & \multirow{8}{*}{0.256} & \multirow{8}{*}{10.03} & \multirow{8}{*}{0.000} & Systemic Cognition & .181 & 2.388 & .018 \\
\hline & & & & $\begin{array}{c}\text { Positivity and } \\
\text { Attunement }\end{array}$ & .087 & .974 & .331 \\
\hline & & & & Positive Attitudes & .045 & .673 & .502 \\
\hline & & & & Spirited Discovery & .082 & 1.008 & .315 \\
\hline & & & & Reflection & .061 & .671 & .503 \\
\hline & & & & Wise Action & .071 & .846 & .398 \\
\hline & & & & Positive Engagement & .106 & 1.157 & .249 \\
\hline & & & & Active Responsiveness & .026 & .302 & .763 \\
\hline \multirow{8}{*}{$\begin{array}{l}\text { The Power } \\
\text { of Second- } \\
\text { order } \\
\text { Cognitive } \\
\text { Control } \\
\text { (Student } \\
\text { Behavioural } \\
\text { Patterns) }\end{array}$} & \multirow{8}{*}{0.386} & \multirow{8}{*}{18.27} & \multirow{8}{*}{0.000} & Systemic Cognition & .236 & 3.433 & .001 \\
\hline & & & & $\begin{array}{l}\text { Positivity and } \\
\text { Attunement }\end{array}$ & .175 & 2.163 & .032 \\
\hline & & & & Positive Attitudes & .069 & 1.137 & .257 \\
\hline & & & & Spirited Discovery & .108 & 1.453 & .148 \\
\hline & & & & Reflection & .084 & 1.008 & .314 \\
\hline & & & & Wise Action & .141 & 1.861 & .064 \\
\hline & & & & Positive Engagement & -.047 & -.564 & .573 \\
\hline & & & & Active Responsiveness & .042 & .531 & .596 \\
\hline
\end{tabular}

The results of the hierarchical multiple regression analysis showed that the cumulative explanatory variance in the FOCHP that is associated with the teacher's encouragement for students to perform learning tasks was (25\%), meaning it is statistically significant at a level greater than $(\sigma=$ 0.05). Meanwhile, the beta coefficient revealed that only one dimension of SI has contributed to the interpretation of teacher encouragement, which is positive engagement as this dimension contributed to increasing FOCHP by (0.192) standard units when it increases by one standard unit.

Furthermore, table (5) shows that the percentage of the cumulative explanatory variance with regard to SOCHP relating to students' motivation was (25.6\%), which is statistically significant at a level greater than $(\sigma=0.05)$. The beta coefficient showed that only systemic cognition clarified the explanation of the students' motivation, contributing to an increase in the variable by (0.181) standard units when systemic cognition increased by one standard unit. Also, the percentage of the cumulative explained variance in terms of the SOCHP of the student's behavioural patterns with regard to overall SI reached (38.6\%), making it statistically significant at a level greater than $(\sigma=0.05)$.

The beta coefficient indicated that two dimensions of SI (systemic cognition and positivity and attunement) affected the students' behavioural patterns; systemic cognition contributed to an increase in the aforementioned variable by (0.236) standard units when systemic cognition increased by one unit, while the positivity and attunement dimension contributed to an increase in the student's behavioural patterns by $(0.175)$ when they increased by one standard unit.

\section{Discussion}

All of the factors of SI allowed for predictions of the learners' cognitive flexibility and cognitive holding power in learning situations through the explained variance ratios. However, the systemic action factor (positive engagement and active responsiveness) was the contributory element in terms of explaining cognitive flexibility (adaptive and automatic). 
The cognitive holding power of the teacher's encouragement of the student in learning tasks ranked first; nevertheless, even though the systemic perception element (systemic cognition/positivity and attunement) ranked second, they both contributed to explaining the SOCHP of students' selfmotivation with regard to performing learning tasks and their behavioural patterns where the systemic thinking factor via reflection contributed to the interpretation of cognitive flexibility.

This result can be attributed to the role played by the factors of $\mathrm{SI}$ in general and the dimension of systemic action in particular in relation to its two dimensions (positive engagement and active responsiveness). This is because it works by urging the learner to practice more cognitive skills, including flexibility (adaptive flexibility) by modifying their way of thinking when encountering certain challenges. However, learners who possess SI factors in general and exhibit systemic action in particular in terms of its dimensions of positive engagement and active responsiveness are more able to pursue appropriate and unconventional solutions to the problems they are confronted by when changing their cognitive style, without being confined by a specific framework.

The major contributions to the explanation of automatic flexibility came from systemic action through positive engagement and systemic thinking via reflection. This finding can be explained in terms of the nature of automatic cognitive flexibility, which is the ability to generate as many ideas about a situation as possible, meaning they are diverse and the individual can move smoothly from one idea to another. This may also be attributed to the correlation of cognitive flexibility with systemic action through positive engagement. It elucidates the practice of cognitive flexibility skills as an intelligent behaviour that indicates $\mathrm{SI}$ is an integrated unit in general via systems of thinking based on reflection and systemic action that in turn have their basis in positive participation; specifically, this relates to dealing with problems in learning situations and urging the learner to diversify their ideas and move smoothly from one concept to another when seeking to solve the problems and challenges they face. This result is consistent with what was proposed by Hamalainen and Saarinen (2010) in relation to the role of systems intelligence in directing thinking dynamically towards realistic, tangible procedural steps and the practical active thinking used by individuals in real-life situations, which requires efficient interaction with the components of complex systems in light of the multiplicity and diversity of forms of feedback.

This result also coincides with what was suggested by Rauthmann (2010) regarding the intelligent responses and successful actions included in SI when there are mutual interactions and feedback between the components of the system on the one hand and elements of the external environment on the other hand. In relation to this, Sadiq and Atta (2020) revealed that there was an indirect influence between SI and positive thinking. Furthermore, Saarinen and Hamalainen (2007) and Ranne (2007) examined what SI represents in terms of awareness of the components of the system, cognisance of the interrelationship between the various elements of the system as well as the ability to determine the appropriate role and engage in productive and successful behaviours. This finding is also consistent with the results of research by Colzato et al. (2006), which suggested that intelligence is positively related to cognitive flexibility, especially when dealing with how events and situations are composed. Additionally, Jaber (2016) reported a statistically significant relationship between the level of systemic thinking and cognitive flexibility.

Systemic intelligence, with its multiple factors, contributes to explaining the FOCHP of the teacher's encouragement of their students to perform learning tasks, and the highest contribution 
came from the action factor through positive engagement. This can be attributed to the general interaction of $\mathrm{SI}$ factors and the systemic action factor, which is specifically represented by positive engagement with the teacher's encouraging activities and practices in relation to the student; collectively, they work to boost the student's motivation to employ various cognitive procedures during the learning process and thus achieve first-order cognitive power.

This explains the role of the teacher in dealing with students at the organisation level, which is represented by the class groups that reflect on the students by encouraging and motivating them as a collective to interact with the elements of the system and actively participate in the performance of learning tasks to attain success and academic achievement. In other words, this equates to the practice of intelligent behaviour at the organisation level with the assistance and support of the teacher. This acts as a catalyst for students to cooperate and communicate effectively, enabling them to gain cognitive control and to move away from the influence of cognitive power in the first place, which is related to the direct role of the teacher in improving the learners' abilities to perform learning-based tasks. Subsequently, they can adopt SOCHP, which is related to the student's self-motivation to deal with learning situations and solve problems.

Indeed, the current study suggests that SI contributes to improving the cognitive holding power associated with student motivation through the systemic perception factor where the student's perception of work requirements within learning groups (the system) lead to an increase in motivation and a more concerted response to learning requirements. The findings of our investigation revealed that $\mathrm{SI}$ and its multiple factors influence the SOCHP of the students' motivation and their behavioural patterns. Moreover, the systemic perception dimension achieved the greatest effect on the students' behavioural patterns and motivation. Meanwhile, positivity and attunement was the most influential factor on the learners' behavioural patterns. This result may be linked to the nature of SOCHP, which requires the practicing of advanced cognitive skills, such as analysis, synthesis and evaluation, to achieve self-learning away from traditional methods of obtaining information that are related to direct dependence on the teacher. Therefore, the factors of SI as well as systemic perception and positivity and attunement increase the student's motivation and modify their behaviour, so they can achieve self-cognitive control and self-learning management.

This coincides with the results of studies by Walmsley (2003) and Xin and Zhang (2009) regarding the role of the learner's perception in activating their increased effort. It also reflects work by D'netto (2004) in relation to performing the required activities and tasks within the learning environment and what was suggested about the role of learner motivation in moving cognitive holding power from the first to the second level to make the self-learning exercise more effective; the learner discovers information by themself, which increases their ability to think, analyse and link this to a conclusion, present new ideas, experiment with them, ask intelligent questions and make decisions.

Our results are also consistent with the findings of a study by Salami (2017), which concluded that there was a positive, statistically significant correlation between $\mathrm{SI}$ and metacognitive thinking skills among university students. In a similar vein to what we uncovered, Saadh (2020) also demonstrated that there is a positive correlation between successful intelligence, positive thinking and the cognitive holding power of university students; the dual presences of a direct effect of positive thinking on cognitive holding power and an indirect effect of positive thinking on successful intelligence via cognitive holding power were also highlighted. 


\section{Conclusion}

Based on the results of this study, we conclude that SI, with its perceptual, cognitive, social, and behavioural factors, contributes to student performance in learning situations through its ability to be flexible and influence cognitive control when performing learning tasks, which are associated with the role the teacher plays in encouraging students to actively participate in learning settings as well the role of the student in relation to their self-motivation to perform learning tasks that stem from their self-awareness, their ability to diversify their thinking and their capacity to modify their learning patterns to attain the required academic achievement.

This investigation also suggested analysing the role of the SI approach through a causal model that links the SI factors (perception, attitude, thinking and action) and the various variables associated with the student in learning situations, such as self-efficacy, motivation to learn, cognitive self-regulation and thinking skills, as it is the correct way to achieve a solid basis for explaining the impact and contribution of $\mathrm{SI}$ at the individual level. Moreover, our research also recommends the integration of systemic thinking skills into different learning activities.

\section{References}

Abdul Wahab. (2011). Mental flexibility and its relationship to both the future time perspective and achievement goals among university faculty members. Journal of Specific Education Research, Special Issue, 20-75.

Canas, J. J., Antoli, A., Fajardo, I. \& Salmeron, L. (2005). Cognitive inflexibility and the development and use of strategies for solving complex dynamic problems: effects of different types of training. Theoretical Issues in Ergonomics Science, 6(1), 95-108. https://doi.org/10.1080/14639220512331311599.

Clark, J \& Dart, B. (1991). Tertiary Learning: A symposium, Paper presented at the Annual Conference of the Australian Association for Research in Education, Ramada Inn, Gold Cosat, December.

https://www.aare.edu.au/data/publications/1991/clarj91044.pdf

Colzato, L., Wouwe, N., Lavender, T. \& Hommel, B. (2006). Intelligence and cognitive flexibility: fluid intelligence correlates with feature "unbinding" across perception and action. Psychon Bull Rev,13(6): 1043-1048. doi:10.3758/bf03213923. PMID: 17484433.

Deak. O. (2003). The Development of Cognitive Flexibility and Language Abilities. Elsevier Science, 31, 272-327. https://psycnet.apa.org/record/2004-12432-007.

Dennis, J. \& Vander Wal, J. (2010). The Cognitive Flexibility Inventory: Instrument Development and Estimates of Reliability and Validity. Cognitive Therapy and Research, 34(3), 241-253. https://link.springer.com/article/10.1007/s10608-009-9276-4

D'netto, M. (2004). The Press for Higher Order Thinking in New Basics Classrooms, Griffith University, Australia.

https://citeseerx.ist.psu.edu/viewdoc/download?doi=10.1.1.505.9991\&rep=rep1\&type=pdf

Draider, M., Abd Al-Sami', M. \& Abd Al-Rahman, A. (2018). Psychometric Efficiency of Cognitive Flexibility Scale for Students of the College of Education in Qena, Journal of Educational Sciences, (37), 75-94. https://maeq.journals.ekb.eg/article_140697_74acdc135c28785596f9d8fe2f3c99a4.pdf 
Feel, H. (2015). Psychometric properties of Tourmanin's systemic intelligence questionnaire on a sample of university students in the light of some demographic variables. Journal of Educational and Social Studies, Helwan University, 21(4), 211-256. file://C:/Users/D.MADHAR/Desktop/62115390.pdf

Gunduz, B. (2013). The Contributions of Attachment Styles, Irrational Beliefs and Psychological Symptoms to the Prediction of Cognitive Flexibility. Educational Consultancy and Research Centre, 13(4), 2079-2085. https://eric.ed.gov/?id=EJ1027682.

Hamalainen, R. \& Saarinen, S. (2010). Essays on Systems Intelligence. Systems Analysis Laboratory Aalto University, School of Science and Technology Espoo, Finland. https://sal.aalto.fi/publications/pdffiles/systemsintelligence2010.pdf.

Hunt, W. \& Stevenson, J. (1997): A Pilot Study of Cognitive Holding Power Associated with Different Degrees of Flexibility In delivery, Australian Vocational Education Review, 4(1), 8-15. https://search.informit.org/doi/abs/10.3316/aeipt.106339

Jaber, A. (2016). Systemic thinking and its relationship to cognitive flexibility among distinguished middle and high school principals and their ordinary counterparts. Unpublished Master's Thesis, University of Babylon, Iraq. https://search.mandumah.com/Record/805370/Details

McCarthy, S. \& Peterson, P. (1995). Students Roles in Classrooms, (In) Anderson, I. (Ed), International Encyclopedia of Teaching and Teacher Education, 2Ed, Vol. 2, p. 408-411

Miyake, A., Friedman, N. P., Emerson, M. J., Witzki, A. H., Howerter, A. \& Wager, T. D. (2000). The unity and diversity of executive functions and their contributions to complex "frontal lobe" tasks: A latent variable analysis. Cognitive psychology, 41(1), 49-100. https://doi.org/10.1006/cogp.1999.0734Get rights and content

Murray, N., Hirt, E. \& Sujan, H. (1990). The influence of mood on categorization: A cognitive flexibility interpretation, Journal of Personality and Social Psychology, 50 (3), 411-425. https://doi.org/10.1037/0022-3514.59.3.411

Rakibat, A. \& Qatami, Y. (2016). The effect of a training program for successful intelligence based on the Sternberg model and metacognitive thinking skills on the degree of critical thinking practice among sixth graders in Jordan. Studies, Educational Sciences, 43(2), 619-635. https://www.researchgate.net/publication/329020396

Ran, R., John, A. \& Shira, Z. (2009). Automatic and flexible, Public Access and PMC Journal, 27 (1), 20-36. https://www.ncbi.nlm.nih.gov/pmc/articles/PMC2659887/

Ranne, R. (2007). Manifestations of the Implicitness of Systems Intelligence in Leadership. Mat-2. 108 Independent Research Project in Applied Mathematics. Helsinki University of Technology. P. 130.

http://salserver.org.aalto.fi/vanhat_sivut/Opinnot/Mat-2.4108/pdf-files/eran07.pdf

Rauthmann, J. (2010). Measuring Trait Systems Intelligence: First steps towards a trait - SI scale (TSIS Alto University School of Science and (R. Hamalainen \& E. Saarinen, Eds.; pp. 89-118).

https://aaltodoc.aalto.fi/bitstream/handle/123456789/102717/isbn9789526031125. pdf?sequence=1\#page=89

Saadh, M. (2020). Modeling causal relationships between positive thinking, cognitive holding power, and successful intelligence among students of the Faculty of Home Economics, Menoufia University. Arabic Research in Specific Education Journals, 20, 83-123. https:// doi.org/10.21608/RAES.2020.117800 
Saarinen, E. \& Hamalainen, R. P. (2007). Systems intelligence: Connecting engineering thinking with human sensitivity (pp. 51-78). https://sal.aalto.fi/publications/pdf-files/rsaa07.pdf

Sadiq, M. \& Atta, S. (2020). Analysis of direct and indirect causal relationships between systemic intelligence, professional ambition, positive thinking, and perceived quality of life for male and female teachers, Journal of Educational Sciences, 1(1), 109-200. https:// doi.org/10.21608/SSJ.2020.146118

Salami, T. (2017). Strategies of systemic intelligence and metacognitive thinking among Saudi university students. Specialized International Educational Journal, 6(12), 56-72. DOI:10.23813/FA/77/5 FA-201903-77C-160

Shah J. Y. (2003). How representations of significant others implicitly, Automatic for the people: affect goal pursuit. The Journal of Personality and Social Psychology, 84 (38), 388-402. https://psycnet.apa.org/buy/2003-02410-002.

Somuncu, D. (2016). Turkish EFL Learners' Use of Communication Strategies and Its Predictors. International Association of Research, 5(3), 178-192. https://dergipark.org.tr/en/pub/eltrj/issue/28554/304669.

Sternberg, R. J. (1985), Beyond IQ. Matriarchic of Human Intelligence. Cambridge, Uni- Press, New York. https://journals.sagepub.com/doi/abs/10.1177/001698628703100112

Stevenson, J \& Mckavanagh, C. (2002). Problem- Solving Cognitive Activity in Technical Education Classrooms, Paper Presented in A Symposium on Problem Solving Activity Changing Minds, European Association for Research on Learning and instruction 10th international conference on Thinking. Harrogate. England pp. 8-10. http://search.informit.com.au/documentSummary;dn=153810;res=AEIPT

Stevenson, J. \& Evans, G. (1994). Conceptualization and measurement of cognitive holding power. Journal of Educational Measurement, 31(2), 161-181. https://doi.org/10.1111/j.1745-3984.1994.tb00441.x.

Stevenson, J. \& Ryan, J. (1994). Cognitive Holding Power Questionnaire, Manual, Centre for Skill Formation Research and Development. Griffith University, Nathan.

Stevenson, J. (1990). Conceptualization and measurement of Cognitive Holding Power in technical and further education learning settings. An annual conference of the Australian Association for Research in Education, Sydney. https://www.aare.edu.au/data/publications/1990/steve90481.pdf

Stevenson, J. (1998): Performance of The Cognitive Holding Power Questionnaire in Schools, Learning and Instruction, 8(5), 393-410. https://doi.org/10.1016/S0959-4752(97)00029-7

Stevenson, J. \& Mckavanagh, C. (1991). Cognitive structures developed in TAFE classes. The Conference of the Australian Association for Research in Education, Australia. https://www.aare.edu.au/data/publications/1991/stevj91227.pdf

Tan, M. (2005). Examining the Impact of an Outward-Bound Singapore Program on the Life Effectiveness of Adolescents. M.A Theses, University of New Hampshire. https://citeseerx.ist.psu.edu/viewdoc/download?doi=10.1.1.535.5812\&rep=rep1\&type=pdf.

Tormanen, J \& Saarinen, E. (2016). Systems intelligence inventory. The Learning Organization, 23(4), 218-231.

https://www.emerald.com/insight/content/doi/10.1108/TLO-01-2016-0006/full/html

Tormanen, J. (2012). Systems intelligence inventory. Master's Thesis, Aalto University Finland. http://systemsintelligence.aalto.fi/tormanen.pdf.

Walmsley, B. (2003). Partnership-Centered Learning: The Case for Pedagogic Balance in Technology Education. Journal of Technology Education, 14(2), 56-69. https://eric.ed.gov/?id=EJ667402 
Alzubi, E. M; Attiat, M. M. \& Al-Adamat, O. A. (2022). Systemic intelligence predictors of cognitive flexibility and cognitive holding power among university students. Cypriot Journal of Educational Science. 17(2), 491-505. https://doi.org/10.18844/cjes.v17i2.6835

Warner, R. (2008). Applied Statistics-from Bivariate through Multivariate Techniques. Sage publications, Inc. https://psycnet.apa.org/record/2007-00676-000

Xin, Z. \& Zhang, L. (2009). Cognitive holding power, fluid intelligence, and mathematical achievement as predictors of children's realistic problem-solving. Learning and Individual Differences, 19(1), 124-129. https://doi.org/10.1016/j.lindif.2008.05.006 